Morison's report, that he has appended to it some valuable tables, pointing out the various forms of the disorder, its causes, and duration; together with the ages of the patients, the number of relapses, \&c. \&c., in 562 cases under treatment on his side of the hospital. All these tables are suppressed; why or wherefore, no reasonable man can divine. The governors may rest assured that the public will not be satisfied with imperfect publications : the odium attached to partial publication is far heavier than the odium attached to entire secrecy. The governors must close and lock up their doors altogether, or they must throw them wide open; if they attempt a middle course, they will soon have them torn from their hinges.

Again: from the only table published with the report, it appears that the number of cases in the year 1840, amongst the curable patients, was to the number of curable patients admitted as 173.308 , or 56.67 per cent.-an unusually large a verage, and stated so to be in Dr. Monro's report; in truth, the ordinary average does not exceed 50 or 52 per cent. Now, Dr. Morison says, " From the table presented to the court, it appears that of 562 cases of insanity under my care, 393 , or very nearly seventy per cent., have been discharged well." Now, assuming this statement to be correct, this conclasion inevitably follows (the number of patients being equally divided between the two physicians), that the cures on Dr. Monro's side cannot exceed 35 per cent., that is to say, one-half of the cures effected by Dr. Morison, as this, the whole number discharged cured, communibus annis, is $\mathbf{5 2}$ to 59 per cent. The number cured by $\mathrm{Dr}$. Morison communibus annis is 70 per cent., ergo, the number cured by Dr. Monro communibus annis is 35 per cent. This cannot be; some fallacy must exist some where, but it cannot be detected without the assistance of the tables. How unjust towards Dr. Monro is their exparte publication!

It is to be hoped now that the attention of the governors is called to the subject, that these errors will be corrected, and that the future reports of the physicians will be worthy of their own high reputation, and of the splendid establishment to which they belong; and it would be well if they adopted the old maxim, that unity is strength, and made their report jointly instead of separately. Rome was not built in a day, and Bethlem cannot be remodelled in 365 days; but $I$ am greatly mistaken if the governors are not so inoculated with the spirit of improvement, that that system of management will daily become more perfect, and the reports of 1846 announce the number of cures to be nearer 80 per cent. than 50. I am, Sir, your obedient servant,

June 14, 1841.

\section{BETHLEM HOSPITAL.}

To the Editor of The Lancet,

SIR :-The manner in which you exposed and removed some of the abuses in our profession, through your publication of them in THE LANCET, assures me that some information conveyed to the public relative to this place would be also of great service; and trusting that you are, sir, actuated by a sincere and disinterested desire to do good, I hope you will kindly receive that as my ex. cuse for the liberty $I$ am now taking, and permit me to remain, Sir, your obliged servant,

Bethlem Hospital, June, 1 S41.

Robert Dawson,

First. On the reception of a patient into Bethlem, his being taken before the committee for examination (as to his fituess) is to him a cruel mockery: he is never allowed to speak, nor is a question put to him. He is placed at the door, with a keeper at each side of him, and if he offer to say a word he is immediately dragged away by them, as was the case only yesterday (June 4). All that concerns him is lefi entirely to the apothecary or steward ; from which cause many patients have been told by their keeper, in a few days after admission, "Why, there seems nothing the matter with you! there was no need of sending you here;" and if the patient is quiet, and his friends are not very anxious for his detention, he may get out in a month or six weeks. Of this sort several instances have occurred within the last twelvemonths, one of a youth of fourteen years of age! and at this moment there is a respectable man, of seventy-seven, from Lewes, in Sussex, who has been detained several weeks with nothing but the imbecility of age as the excuse.

Second. On the patient's entrance, he is at once ushered into one common yard, and indiscriminately mixed with from seventy to ejghty persons of all sorts, incurable, dirty, furious, idiotic, clean, and respectable, are all huddled together, and greeted with the idle curiosity and troublesome importunity of the old stagers for tobacco or snuff, to whom the fresh inmates are a little amusement at first, not unfrequently coming from, or knowing some of, their neighbourhood, After staying in this yard for an hour and a half, or so, he enters his ward, and dines with from twenty to thirty, off a wooden plate, with a bone knife and fork; and in rather more than half an hour he is again returned to the yard, to feel his helpless misery. At five o'clock the patient is again returned to his ward for his supper, and then allowed to amuse himself till eight, when he goes to bed: on doing which he receives an aperient powder, and is immedi. 
